\title{
Perfectionism and negative/positive affect associations: the role of cognitive emotion regulation and perceived distress/coping
}

\author{
Associação entre perfecionismo e afeto negativo e positivo: o papel da \\ regulação emocional cognitiva e do stresse/coping percebidos
}

Juliana Castro, Maria João Soares, Ana T. Pereira, António Macedo*

\begin{abstract}
Objective: To explore 1) if perfectionism, perceived distress/ coping, and cognitive emotion regulation (CER) are associated with and predictive of negative/positive affect (NA/PA); and 2) if CER and perceived distress/coping are associated with perfectionism and if they mediate the perfectionism-NA/PA associations. There is a distinction between maladaptive and adaptive perfectionism in its association with NA/PA. CER and perceived distress/coping may mediate the maladaptive/adaptive perfectionism and NA/PA associations.

Methods: 344 students (68.4\% girls) completed the Hewitt \& Flett and the Frost Multidimensional Perfectionism Scales, the Composite Multidimensional Perfectionism Scale, the Profile of Mood States, the Perceived Stress Scale, and the Cognitive Emotion Regulation Questionnaire.

Results: NA predictors were maladaptive/adaptive perfectionism, maladaptive CER and perceived distress (positively), positive reappraisal and planning, and perceived coping (negatively). PA predictors were maladaptive/adaptive perfectionism and perceived distress (negatively), positive reappraisal and planning, positive refocusing and perceived coping (positively). The association between maladaptive perfectionism and NA was mediated by maladaptive CER/low adaptive CER, perceived distress/low coping. Maladaptive perfectionism and low PA association was mediated by perceived distress. High PA was determined by low maladaptive perfectionism and this association was mediated by adaptive REC and coping. Adaptive perfectionism and NA association was mediated by maladaptive CER and perceived distress.

Conclusion: CER and perceived distress/coping are associated and mediate the perfectionism-NA/PA associations.

Keywords: Perfectionism, cognitive emotion regulation, perceived stress/coping, negative affect, positive affect.
\end{abstract}

\begin{abstract}
Resumo
Objetivo: Explorar 1) se o perfeccionismo, o estresse/coping percebidos e a regulação emocional cognitiva (REC) estão associadas e predizem o afeto negativo/positivo (AN/AP); e 2) se a REC e o estresse/coping estão associados e mediam a relação perfeccionismo-AN/AP. Existe uma distinção entre o perfeccionismo mal-adaptativo/adaptativo na associação com o AN/AP. A REC e o estresse/coping poderão mediar as associações entre o perfeccionismo mal-adaptativo/adaptativo-AN/AP.

Métodos: 344 estudantes (68.4\% do sexo feminino) completaram as Escalas Multidimensionais do Perfeccionismo de Hewitt \& Flett e de Frost, a Escala Multidimensional de Perfeccionismo Compósita, o Perfil dos Estados de Humor, a Escala de Estresse Percebido e o Questionário da Regulação Emocional Cognitiva.

Resultados: Os preditores do AN foram o perfeccionismo adaptativo/mal-adaptativo, a REC mal-adaptativa e o estresse percebido (positivamente), a reavaliação positiva e planeamento e o coping (negativamente). Os preditores do AP foram o perfeccionismo adaptativo/mal-adaptativo e o estresse percebido (negativamente), a reavaliação positiva e planeamento, a refocalização positiva e o coping percebido (positivamente). A associação entre o perfeccionismo mal-adaptativo e o AN foi mediada pela REC maladaptativa/baixa REC adaptativa, pelo estresse/baixo coping percebidos. A associação entre o perfeccionismo mal-adaptativo/ adaptativo e baixo AP foi mediada pelo estresse percebido. $O$ elevado AP foi determinado pelo baixo perfeccionismo maladaptativo e esta associação foi mediada pela REC adaptativa e pelo coping. A associação entre o perfeccionismo adaptativo e o AN foi mediada pela REC mal-adaptativa e pelo estresse percebido.

Conclusão: A REC e o estresse/coping percebidos estão associados e medeiam as associações entre o perfeccionismo e AN/AP.

Descritores: Perfecionismo, regulação emocional cognitiva, estresse/coping percebidos, afeto negativo, afeto positivo.
\end{abstract}

\footnotetext{
* Departamento de Psicologia Médica, Faculdade de Medicina, Universidade de Coimbra, Coimbra, Portugal. Submitted Jun 08 2016, accepted for publication Dec 282016.

Suggested citation: Castro J, Soares MJ, Pereira AT, Macedo A. Perfectionism and negative/positive affect associations: the role of cognitive emotion regulation and perceived distress/coping. Trends Psychiatry Psychother. 2017;39(2):77-87. http://dx.doi.org/10.1590/2237-6089-2016-0042
} 


\section{Introduction}

Frost et al. ${ }^{1}$ defined perfectionism as "the setting of excessively high standards for performance accompanied by overly critical self-evaluation." Perfectionism has been a topic of increased interest in recent years, because of its association with stress generation and maintenance ${ }^{2}$ and with several psychopathological conditions, being considered a transdiagnostic process. ${ }^{3}$ Recent research has given support to the notion that perfectionism is multidimensional in nature and has both personal and interpersonal facets, some of which are adaptive, and some of which have more detrimental consequences for the individual. The perfectionism dimensions more frequently associated with psychopathology are concerns over mistakes (CM) and doubts about actions (DA) from the Frost-Multidimensional Perfectionism Scale (F-MPS), ${ }^{1}$ and socially prescribed perfectionism (SPP) from the Hewitt and Flett Multidimensional Perfectionism Scale (H\&F-MPS). ${ }^{4,5}$ Self-oriented perfectionism (SOP) and personal standards (PS), from the H\&F-MPS and F-MPS, respectively, are considered the most adaptive dimensions of perfectionism. ${ }^{5,6}$

Based on factor analysis of F-MPS and H\&F-MPS items, a model has been proposed that incorporates two factors. One of these factors is evaluative concerns $(E C)$, which involves self-critical tendencies and includes CM, SPP, DA, parental expectations (PE) and parental criticism ( $P C)$. This factor is essentially maladaptive, being related to negative outcomes, such as higher levels of depression, anxiety and stress.6,7 The other factor is positive strivings (PStr), which involves the setting and striving for high standards and goals, including PS, SOP, organization and other-oriented perfectionism. It is associated with positive characteristics, processes and outcomes and is unrelated or even inversely related to negative characteristics. However, the distinction between the positive and negative aspects of perfectionism is not straightforward. ${ }^{5,6}$

Negative affect (NA) is a stable and heritable trait tendency to experience a broad range of negative feelings such as worry and self-criticism, and to have a negative self-image. ${ }^{8} \mathrm{NA}$ is described as a transdiagnostic factor for depression and anxiety. ${ }^{9}$ Positive affect (PA), in turn, is one aspect of pleasurable and positive life experiences. The high energy and engagement, optimism, and social interest that characterize individuals with higher levels of PA suggest that they are more likely to be satisfied with their lives. ${ }^{10}$ According to the diathesis-stress model, ${ }^{11}$ perfectionism may interact with stress to predispose individuals to NA. Therefore, perfectionism (the diathesis) is considered a relatively stable vulnerability trait. This stability does not exclude that perfectionism trait is also state dependent, and some of its characteristics may be exacerbated by affective states, such as depressive symptoms. As a stable personality trait, perfectionism involves a temporal and spatial coherent pattern of cognitions, and it affects behavior and motivation. Cognitive characteristics and cognitive emotion regulation (CER) mechanisms associated with perfectionism are prime candidates for investigation when we intend to explore the association between perfectionism and negative or positive outcomes, such as NA, psychological distress/ psychopathology or PA.

As postulated in Beck's cognitive model of depression, dysfunctional cognitions are deviations from accurate thought content that occur automatically regarding one's self or the world. Dysfunctional cognitions have been associated with many psychopathological conditions and dispositional factors, including perfectionism. ${ }^{12} \mathrm{~A}$ negative perfectionistic cognitive style has been implicated in the development and maintenance of NA, especially after individuals experience stressful life events, and both negative and positive cognitions seem to be important to understand how perfectionism is related to subjective well-being. ${ }^{13}$ The perfectionistic cognitive style is also implicated in psychiatric disorders, for example, dichotomous thinking and rumination. ${ }^{14,15}$ One possible explanation for this is that these dysfunctional cognitive processes (e.g. rumination) impact negatively on emotion regulation. Even though emotions are biologically based, people are able to influence their emotions as well as the way they are expressed. ${ }^{16}$ The regulation of emotions by cognitions or thoughts (CER) helps people to keep control over their emotions during or after threatening or stressful events, ${ }^{17,18}$ and is a critical process in initiating, motivating and organizing adaptive behavior. ${ }^{19}$

Garnefskiet al. ${ }^{17}$ conceptualized nine cognitive emotion coping strategies that are typically used in response to stressful events. Four of them may be considered "less adaptive" and are related to negative responses: self-blame, blaming others, rumination and catastrophizing. The other five dimensions are related to more positive or adaptive coping responses: acceptance, refocus on planning, positive refocusing, positive reappraisal and putting into perspective. Results from studies revealed that self-blame, rumination and catastrophizing were positively associated with negative emotions. In contrast, positive reappraisal and positive refocusing had negative associations with depression and anxiety. ${ }^{17,19,20}$ Positive reappraisal also had a positive connection with PA. ${ }^{21}$

Concerning the association between perfectionism and the Cognitive Emotion Regulation Questionnaire (CERQ) dimensions, literature findings showed that both 
maladaptive and adaptive perfectionism were related to negative CERQ dimensions. Thus, SOP, PS, CM and SPP were associated with self-blame, 19,22 and PS and SPP were associated with rumination. ${ }^{19,23}$ Rudolph et al. showed that SPP was related to self-blame, rumination and catastrophizing and to lower levels of positive reappraisal and planning and putting into perspective, and that SOP was associated with self-blame as well as with depression. ${ }^{20}$ Literature findings also suggested that coping strategies, daily hassles, event stress, coping resources, and social resource appraisals have an important mediation role in the association between perfectionism and psychological distress, such as $\mathrm{NA} /$ emotions, $^{24-26}$ or may interact with perfectionism to predict $\mathrm{PA}$ and/or NA. ${ }^{27}$ To our knowledge, there are no studies exploring the mediation role of CERQ dimensions in perfectionism and NA/PA associations. In addition, the role of CER and of perceived distress/ coping in the association between adaptive/maladaptive perfectionism and PA has been scarcely explored.

The aims of this paper were: 1) to explore if perfectionism, perceived distress/coping and CER are associated with and predictive of NA/PA; and 2) to analyze if CER and perceived distress/coping are associated with perfectionism and if they mediate the associations between perfectionism and NA/PA. Figure 1 represents the model that was explored in the present study.

\section{Method}

This study was approved by the ethics committee of the local institution where it was developed.

\section{Participants}

Data collection was performed at a university in September 2012, i.e., not including the exam period. The study aims were explained to the students, confidentiality was ensured, and they signed an informed consent form. The participants were recruited by convenience. The students were 344 medical students (68.4\% female). Their mean age was $20.69 \pm 1.586$ years, and there was no significant gender difference in age (females $=20.73 \pm 1.584$ vs. males $=20.61 \pm 1.595$; $\left.t_{336}=-0.619\right)$. More than half of the participants ( $54.2 \%$, $n=182)$ were 4 th-year students; $26.2 \%(n=88)$ were enrolled in the first three years, and $19.6 \% \quad(n=66)$ were 5th-year students.

\section{Instruments}

All the questionnaires used in the present study showed good reliability and/or internal validity in Portuguese samples.

\section{Perfectionism}

The Portuguese version of the H\&F-MPS comprises 45 statements that evaluate SOP, SPP and otheroriented perfectionism. ${ }^{28}$ For this study, only SPP and SOP statements were used. Items were answered using a 7-point scale ranging from strongly disagree to strongly agree.

The Portuguese version of the F-MPS was used to measure PS, DA, CM, PE, PC and organization. ${ }^{29}$ The F-MPS comprises 35 statements; for this study, the 24-item version of the F-MPS was used. ${ }^{30}$ Items were answered using a 5-point scale ranging from strongly disagree to strongly agree.

To measure EC and PStr, the Portuguese version of the Composite Multidimensional Perfectionism Scale ${ }^{31}$ was used.

\section{NA and PA}

The Portuguese version of the Profile of Mood States (PoMS) was used to evaluate NA and PA. ${ }^{32}$ The original version consists of 65 adjectives assessing seven dimensions: tension-anxiety, anger-hostility, fatigueinertia, depression-dejection, confusion-bewilderment and vigor-activity. In some samples, the dimension friendliness is included. PoMS items were answered using a 5-point scale ranging from not at all to extremely. In

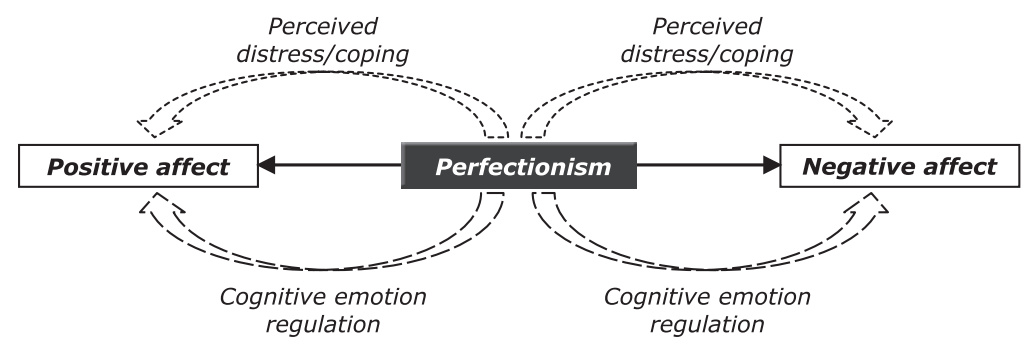

Figure 1 - Cognitive emotion regulation and perceived distress/coping as possible mediators of the association between perfectionism and negative/positive affect. 
the present study, NA was assessed by summing the scores obtained for tension-anxiety, anger-hostility, fatigue-inertia and depression-dejection, and PA corresponded to vigor-activity score.

\section{Perceived distress/coping}

To measure perceived distress, the Portuguese version of the Perceived Stress Scale-10 (PSS-10) was used. ${ }^{33}$ Items were answered using a 5-point scale ranging from never to very often. Factor analysis using varimax rotation, which was performed in the sample of the present study, revealed two factors that were inversely correlated $(r=-0.541 ; p<0.01)$, namely, perceived distress (explained variance [EV] 44.11\%; $\mathrm{a}=0.819$ ) and perceived coping (EV 12.54\%; $\mathrm{a}=0.754$ ) (data not published).

\section{CER}

The Portuguese version of the CERQ was used to evaluate positive reappraisal and planning (EV 22.86\%; $a=0.89$ ), positive refocusing ( $E V 15.59 \% ; a=0.86$ ), rumination (EV $6.45 \% ; a=0.78$ ), blaming others (EV $4.92 \% ; a=0.79$ ), putting into perspective (EV 4.11\%; $a=0.80$ ), self-blame (EV 3.71\%; $a=0.76$ ), acceptance (EV 3.51\%; $a=0.70$ ) and catastrophizing (EV 3.25\%; $a=0.74$ ) (total scale $E V=59.96 \% ; a=0.89) .{ }^{34}$ The items were answered using a 5 -point scale ranging from never to always.

\section{Statistical analysis}

All data analyses were performed using the Statistical Package for the Social Sciences (SPSS), version 19 for Windows. Descriptive statistics were determined. Parametric or non-parametric tests were used according to the normality of variable distribution. Pearson's or Spearman's correlation coefficients were used to calculate the associations between variables. The magnitude of associations was classified according to Cohen's criteria: 0.01 , low; 0.30, moderate; and 0.50, high. ${ }^{35}$

Simple and multiple linear regression analyses were performed. Only variables showing significant correlations with the dependent variables were entered in the regression model as independent variables.

Simple mediation analysis with Bootstrapping methodology ${ }^{36,37}$ was used to study the explanatory role of a mediator variable $(M)$ in the causal association between an independent variable $(X)$ and a dependent variable $(Y)$. Bootstrap confidence intervals for indirect effects were calculated with 5,000 bootstrap resample. An indirect effect of $X$ on $Y$ was considered significant when the interval for its 5,000 bootstrap estimates, with $95 \%$ of confidence interval $(95 \% \mathrm{CI})$, did not contain zero.

\section{Results}

\section{Correlations between NA/PA and perfectionism}

NA was positively correlated with EC, SPP, CM, DA, PC, $P E$ (from $r=0.162$ to $r=0.524$; all $p<0.01$ ), PStr, PS and SOP (from $r=0.157$ to $r=0.169 ; p<0.01$ ) and inversely correlated with organization $(r=-0.181 ; p<0.01)$.

$\mathrm{PA}$ was significantly and negatively correlated with $E C, C M, D A, S P P$ (from $r=-0.267$ to $r=-0.374 ; p<0.01$ ), PC $(r=-0.124 ; p<0.05)$, PStr and SOP (from $r=0 .-122$ to $r=-0.154 ; p<0.01)$.

\section{Correlations between NA/PA and CER}

NA was positively correlated with rumination, blaming others, self-blame, and catastrophizing (from $r=0.307$ to $r=0.421 ; p<0.01$ ), and inversely correlated with positive reappraisal and planning, positive refocusing and putting into perspective $(r=-0.237$ to $r=-0.372 ; p<0.01)$.

PA was only positively correlated with adaptive CER mechanisms, namely positive reappraisal and planning, positive refocusing, putting into perspective and acceptance (from $r=0.189$ to $r=0.432 ; p<0.01$ ).

\section{Correlations between NA/PA and perceived distress/coping}

NA and PA were associated, in opposite ways, with perceived distress $(r=0.727 ; r=-0.528$, respectively) and with perceived coping $(r=-0.581 ; r=0.529$, respectively) (all $\mathrm{p}<0.1$ ).

\section{Correlations between perfectionism and CER}

PS, SOP and PStr were not significantly correlated with adaptive CER. PS was positively associated with higher levels of blaming others $(r=0.175)$ and selfblame $(r=0.210)$. SOP was positively associated with self-blame $(r=0.201)$ and catastrophizing $(r=0.141)$ (all $\mathrm{p}<0.01$ ). PStr was positively associated with rumination, blaming others, catastrophizing (from $r=0.112$ to $r=0.133$; all $p<0.05$ ) and self-blame $(r=0.225 ; p<0.01)$. Organization showed a positive association with positive reappraisal and planning, positive refocusing and putting into perspective (from $r=0.162$ to $r=0.259$; all $p<0.01)$, and was negatively related to self-blame $(r=-0.136 ; p<0.01)$.

CM, DA, SPP and EC were positively correlated with all maladaptive CER dimensions (from $r=0.147$ to $r=0.418$; all $p<0.01$ ). 
PC and PE were positively correlated with selfblame, blaming others, and catastrophizing (from $r=0.148$ to $r=0.288$; all $p<0.01$ ). Additionally, $C M$, DA, SPP, PC, PE and EC were negatively correlated with positive reappraisal and planning (from $r=-$ $0.126[p<0.05]$ to $r=-0.378[p<0.01])$, and all of these perfectionism dimensions (excluding PE) were negatively correlated with positive refocusing and putting into perspective $(r=-0.125[p<0.05]$ to $r=-$ $0.270[p<0.01]) . C M$ was negatively associated with acceptance $(r=-0.163 ; p<0.01)$.

\section{Correlations between perfectionism and perceived distress/coping}

CM, DA, SPP, PC, PE and EC as well as SOP, PS and PStr were positively associated with high perceived distress (from $r=0.167$ to $r=0.467$; all $p<0.01$ ). $C M$, DA, PC, PE and SPP were negatively correlated with perceived coping (from $r=-0.166$ to $r=-0.323$; all $p<0.01)$, and organization $(r=0.144 ; p<0.01)$ was positively correlated with it. PStr, SOP and PS were not significantly associated with perceived coping.

\section{Regression analysis: NA/PA as dependent variables}

Table 1 shows the results of the regression model considering NA/PA as dependent variables.

\section{Regression analysis: perfectionism as independent variable}

The linear regression analysis revealed that EC and PStr explained 29.6 and $2.7 \%$ of the NA total variance, respectively, and both were significant predictors of NA. H\&F/F-MPS dimensions globally explained $37.5 \%$ of the NA total variance, and DA, SPP and CM were the significant predictors of it.

EC and PStr explained 9.4 and $1.5 \%$ of the PA total variance, respectively, and both were negative significant predictors of it. H\&F/F-MPS dimensions globally explained $14.7 \%$ of the PA total variance, and $\mathrm{CM}$ was its unique significant negative predictor.

\section{Regression analysis: CER as independent variable}

The multiple regression analysis revealed that CERQ dimensions globally explained $34.9 \%$ of the NA total variance, but only blaming others, self-blame and catastrophizing (positively) and positive reappraisal and planning (negatively) were significant predictors of
NA (all $p<0.01$ ). Also, the multiple regression analysis revealed that adaptive CERQ dimensions globally explained $19 \%$ of the PA total variance $(p<0.01)$; significant predictors of PA were positive reappraisal and planning $(p<0.01)$ and positive refocusing $(p<0.05)$.

\section{Regression analysis: perceived distress/ coping as independent variable}

The linear regression analysis showed that perceived distress and perceived coping explained 52.7 and $33.6 \%$ of the total variance of NA, respectively, and were positive and negative significant predictors of it, respectively (both $\mathrm{p}<0.01$ ).

Perceived distress and perceived coping also explained 27.6 and $27.7 \%$ of the PA total variance, respectively, and were negative and positive predictors of it, respectively (both $\mathrm{p}<0.01$ ).

\section{Perfectionism and NA association: perceived distress/coping and CER as possible mediators}

Only those perfectionism dimensions showing a significant contribution to the explanation of NA variance in the previous regression analyses, namely DA, SPP, CM, EC and PStr, were selected to be explored as independent variables in mediation analyses. Perceived distress/coping and maladaptive/adaptive CER strategies were explored as possible mediators of the association between perfectionism and NA.

\section{Mediation role of maladaptive CER}

The results of mediation analyses showed that the association between DA and NA was partially mediated by rumination, blaming others, self-blame and catastrophizing (indirect effect [IE] $=0.371$, $95 \% \mathrm{CI}=0.159 / 0.697 ; \mathrm{IE}=0.401,95 \% \mathrm{CI}=0.155 / 0.747$; $\mathrm{IE}=0.410 ; \quad 95 \% \mathrm{CI}=0.105 / 0.744 ; \quad \mathrm{IE}=0.632$ ， $95 \% \mathrm{CI}=0.332 / 1.051 ;$ respectively). These maladaptive CER dimensions also partially mediated the association between SPP and NA (IE =0.130, 95\%CI =0.059/0.239; $\mathrm{IE}=0.158, \quad 95 \% \mathrm{CI}=0.061 / 0.274 ; \quad \mathrm{IE}=0.161$, $95 \% \mathrm{CI}=0.062 / 0.278 ; \mathrm{IE}=0.304,95 \% \mathrm{CI}=0.167 / 0.457$; respectively), between $\mathrm{CM}$ and $\mathrm{NA} \quad(\mathrm{IE}=0.331$, $95 \% \mathrm{CI}=0.077 / 0.703 ; \mathrm{IE}=0.380,95 \% \mathrm{CI}=0.115 / 0.786$; $\mathrm{IE}=0.581 ， \quad 95 \% \mathrm{CI}=0.257 / 1.021 ; \quad \mathrm{IE}=0.866$, $95 \% \mathrm{CI}=0.466 / 1.457$; respectively) and between $\mathrm{EC}$ and NA (IE $=0.065,95 \% C I=0.027 / 0.127 ; \mathrm{IE}=0.086$, $95 \% \mathrm{CI}=0.031 / 0.163 ; \mathrm{IE}=0.081,95 \% \mathrm{CI}=0.025 / 0.153$; $\mathrm{IE}=0.175,95 \% \mathrm{CI}=0.100 / 0.273$; respectively).

PStr and NA association was partially mediated by rumination, blaming others and catastrophizing 
$(\mathrm{IE}=0.046, \quad 95 \% \mathrm{CI}=0.006 / 0.104 ; \quad \mathrm{IE}=0.058$ ， $95 \% \mathrm{CI}=0.011 / 0.125 ; \mathrm{IE}=0.082,95 \% \mathrm{CI}=0.021 / 0.155$; respectively) and fully mediated by self-blame ( $\mathrm{IE}=0.101,95 \% \mathrm{CI}=0.047 / 0.177$ ) (Figure 2).

DA, CM, PSP, EC and PStr dimensions were associated with significantly high levels of rumination, blaming others, self-blame and catastrophizing, which in turn were associated with significantly increased levels of NA. However, while self-blame was a necessary condition for the association between PStr and NA, the other CER dimensions strengthened the relationship between these variables.

\section{Mediation role of adaptive CER mechanisms}

Positive reappraisal and planning, positive refocusing and putting into perspective partially mediated the association between $\mathrm{CM}$ and NA (IE=0.731, $95 \% \mathrm{CI}=0.381 / 1.20 ; \mathrm{IE}=0.290$, IC $95 \%=0.063 / 0.633$;

Table 1 - Regression models with negative/positive affect as dependent variables

\begin{tabular}{|c|c|c|c|c|}
\hline Independent variable/predictor & $\mathbf{R}^{2}$ & Adjusted $\mathbf{R}^{2}$ & F change (df) & Beta \\
\hline \multicolumn{5}{|c|}{ Negative affect (dependent variable) } \\
\hline H\&F/F-MPS & 0.389 & 0.375 & $\mathrm{~F}_{8,329}=26.24 *$ & \\
\hline Organization & & & & -0.041 \\
\hline Personal standards & & & & 0.035 \\
\hline Concerns over mistakes & & & & $0.202 *$ \\
\hline Doubts about actions & & & & $0.305 *$ \\
\hline Parental expectations & & & & -0.110 \\
\hline Parental criticism & & & & 0.098 \\
\hline Socially prescribed perfectionism & & & & $0.275 *$ \\
\hline Self-oriented perfectionism & & & & -0.107 \\
\hline \multicolumn{5}{|l|}{ Composite MPS } \\
\hline Evaluative concerns & 0.296 & 0.294 & $\mathrm{~F}_{1,337}=141.533 *$ & $0.544 *$ \\
\hline Positive striving & 0.027 & 0.024 & $F_{1,336}=9.354 *$ & $0.165 *$ \\
\hline Cognitive emotion regulation & 0.362 & 0.349 & $\mathrm{~F}_{7,332}=26.941 *$ & \\
\hline Positive reappraisal and planning & & & & $-0.268 *$ \\
\hline Positive refocusing & & & & 0.014 \\
\hline Rumination & & & & 0.090 \\
\hline Blaming others & & & & $0.121^{+}$ \\
\hline Putting into perspective & & & & -0.094 \\
\hline Self-blame & & & & $0.129^{+}$ \\
\hline Catastrophizing & & & & $0.275 *$ \\
\hline Perceived stress (PSS-F1) & 0.528 & 0.527 & $F_{1,338}=378.494 *$ & $0.724 *$ \\
\hline Perceived coping (PSS-F2) & 0.338 & 0.336 & $F_{1,338}=172.596 *$ & $-0.581 *$ \\
\hline \multicolumn{5}{|l|}{ Positive affect (dependent variable) } \\
\hline H\&F/F-MPS & 0.159 & 0.147 & $\mathrm{~F}_{5,333}=12.641 *$ & \\
\hline Concerns over mistakes & & & & $-0.283 *$ \\
\hline Doubts about actions & & & & -0.088 \\
\hline Parental criticism & & & & 0.026 \\
\hline Self-oriented perfectionism & & & & 0.019 \\
\hline Socially prescribed perfectionism & & & & -0.112 \\
\hline \multicolumn{5}{|l|}{ Composite MPS } \\
\hline Evaluative concerns & 0.097 & 0.094 & $\mathrm{~F}_{1,338}=36.309 *$ & $-0.311 *$ \\
\hline Positive striving & 0.015 & 0.012 & $\mathrm{~F}_{1,337}=5.117^{*}$ & $-0.122^{+}$ \\
\hline Cognitive emotion regulation & 0.200 & 0.190 & $\mathrm{~F}_{4,336}=20.954^{*}$ & \\
\hline Positive reappraisal and planning & & & & $0.324 *$ \\
\hline Positive refocusing & & & & $0.131^{+}$ \\
\hline Putting into perspective & & & & 0.036 \\
\hline Acceptance & & & & 0.013 \\
\hline Perceived stress (PSS-F1) & 0.279 & 0.276 & $F_{1,139}=130.929 *$ & $-0.528 *$ \\
\hline Perceived coping (PSS-F2) & 0.279 & 0.277 & $F_{1,338}=131.452 *$ & $0.529 *$ \\
\hline
\end{tabular}

CERQ = Cognitive Emotion Regulation Questionnaire; $\mathrm{df}=$ degrees of freedom; H\&F/F-MPS = dimensions of the Hewitt and Flett Multidimensional Perfectionism Scale and Frost Multidimensional Perfectionism Scale; PSS = Perceived Stress Scale.

$* p<0.01$.

$+p<0.05$.

82 - Trends Psychiatry Psychother. 2017;39(2) 
$\mathrm{IE}=0.294, \quad 95 \% \mathrm{CI}=0.063 / 0.645 ; \quad$ respectively $)$, between DA and NA (IE =0.440, 95\%CI=0.199/0.768; $\mathrm{IE}=0.173, \quad 95 \% \mathrm{CI}=0.049 / 0.384 ; \quad \mathrm{IE}=0.150$ ， IC95\% $=0.005 / 0.388$; respectively), between SPP and NA ( $\mathrm{IE}=0.156,95 \% \mathrm{CI}=0.073 / 0.265 ; \mathrm{IE}=0.062$, $95 \% \mathrm{CI}=0.016 / 0.137 ; \mathrm{IE}=0.052,95 \% \mathrm{CI}=0.005 / 0.135$; respectively) and between $\mathrm{EC}$ and NA (IE $=0.097$, $95 \% \mathrm{CI}=0.049 / 0.163 ; \mathrm{IE}=0.037,95 \% \mathrm{CI}=0.012 / 0.079$; $\mathrm{IE}=0.045 ， 95 \% \mathrm{CI}=0.015 / 0.096$; respectively). CM, DA, SPP and EC were predictive of low levels of these adaptive CER strategies, which in turn were associated with increasing NA (Figure 2).

The previous regression analyses also indicated that PStr was predictive of NA but not associated with adaptive CER mechanisms and therefore the mediation analysis was not performed.

\section{Mediation role of perceived distress}

Perceived distress partially mediated the association between $\mathrm{CM}$ and NA (IE=2.22, $95 \% \mathrm{CI}=1.619 / 2.914)$, between DA and NA ( $\mathrm{IE}=1.995$, $95 \% \mathrm{CI}=1.450 / 2.665)$, between SPP and NA ( IE $=0.637$, $95 \% \mathrm{CI}=0.454 / 0.839)$, and between $\mathrm{EC}$ and NA ( $\mathrm{IE}=0.409,95 \% \mathrm{CI}=0.306 / 0.524)$, and fully mediated the association between PStr and NA ( $\mathrm{IE}=0.251$, $95 \% \mathrm{CI}=0.119 / 0.369$ ) (Figure 2). Thus, CM, DA, SPP, EC and PStr were associated with high levels of perceived distress, which in turn were associated with increased levels of NA. However, while perceived distress strengthened the relationship between $C M$, DA, SPP, EC and NA, it was a necessary condition for the association between positive striving and NA.

\section{Mediation role of perceived coping}

Perceived coping was not significantly correlated with PStr, but partially mediated the association between CM and NA (IE $=1.331,95 \% \mathrm{CI}=0.868 / 1.872)$, between DA and $\mathrm{NA}(\mathrm{IE}=1.044,95 \% \mathrm{CI}=0.660 / 1.492)$, between SPP and NA (IE $=0.385,95 \% C I=0.248 / 0.550)$ and between $E C$ and NA ( $\mathrm{IE}=0.232,95 \% \mathrm{CI}=0.152 / 0.330$ ) (Figure 2). Perceived coping strengthened the link between these perfectionism dimensions and NA, in the following way: CM, DA, SPP and EC were associated with low levels of perceived coping, which in turn were associated with high levels of NA.

\section{Perfectionism and PA association: perceived distress/coping and CER strategies as possible mediators}

The previous regression analyses showed that CM, EC and PStr were significant predictors of PA, and therefore they were selected to be independent variables in mediation analyses. Perceived distress/ coping and maladaptive/adaptive CER mechanisms were explored as possible mediators of the association between perfectionism and PA.

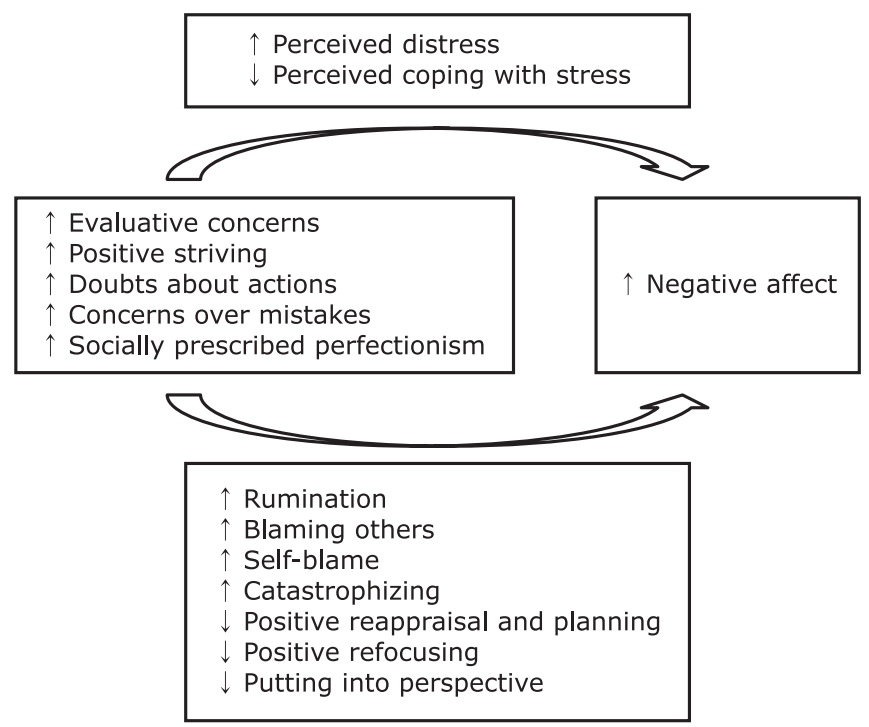

Figure 2 - Cognitive emotion regulation dimensions and perceived distress/coping mediating the association between perfectionism dimensions and negative affect. $\downarrow=$ low levels; $\uparrow=$ high levels. 


\section{Mediation role of maladaptive CER}

Maladaptive CER dimensions were not significantly correlated with PA, and therefore they were not explored as possible mediators.

\section{Mediation role of adaptive CER mechanisms}

Positive reappraisal and planning, positive refocusing, putting into perspective and acceptance partially mediated the association between $\mathrm{CM}$ and $\mathrm{PA}$ ( $\mathrm{IE}=-$ $0.243,95 \% \mathrm{CI}=-0.354 /-0.155 ; \mathrm{IE}=-0.139$, 95\%CI $=-$ $0.229 /-0.074 ; \mathrm{IE}=-0.134,95 \% \mathrm{CI}=-0.204 /-0.052 ; \mathrm{IE}=-$ $0.041,95 \% \mathrm{CI}=-0.100 /-0.009$; respectively). All of these adaptive CER dimensions, excluding acceptance (which was not associated with the EC dimension), partially mediated the association between $\mathrm{EC}$ and $\mathrm{PA}(\mathrm{IE}=-0.032$, $95 \% \mathrm{CI}=-0.050 /-0.019 ; \quad \mathrm{IE}=-0.018, \quad 95 \% \mathrm{CI}=-0.031 /-$ 0.008 ; IE $=-0.014,95 \% \mathrm{CI}=-0.027 /-0.005$; respectively) (Figure 3). Low levels of CM and EC were associated with high levels of positive CER dimensions, which in turn were associated with high PA.

\section{Mediation role of perceived distress}

Perceived distress partially mediated the association between CM and PA (IE $=-0.332,95 \% \mathrm{CI}=-0.451 /-0.231$ ) and totally mediated the association between EC, PStr and PA ( $\mathrm{IE}=-0.070,95 \% \mathrm{CI}=-0.093 /-0.051 ; \mathrm{IE}=-0.039$, $95 \% \mathrm{CI}=-0.060 /-0.022$; respectively) (Figure 3 ). Thus, CM, EC and PStr led to increasing perceived distress, which in turn led to low PA. However, while perceived distress strengthened the link between CM and low PA, it was a necessary condition for the association between EC, PStr and Iow PA.

\section{Mediation role of perceived coping}

Perceived coping partially mediated the association between $\mathrm{CM}$ and $\mathrm{PA} \quad(\mathrm{IE}=-0.273,95 \% \mathrm{CI}=-0.379 /-$
$0.181)$ and fully mediated the association between EC and PA ( $\mathrm{IE}=-0.273,95 \% \mathrm{CI}=-0.379 /-0.181$ ) (Figure 3). Therefore, low levels of CM and of EC led to the increase of perceived coping; this increase, in turn, led to increase of PA. However, while perceived coping strengthened the inverse association between $\mathrm{CM}$ and $\mathrm{PA}$, it was a necessary condition for the inverse association between $\mathrm{EC}$ and PA.

The role of PStr was not explored due to its nonsignificant correlation with perceived coping.

\section{Discussion}

One of the main goals of the present study was to analyze if perfectionism, CER strategies and perceived distress/coping were associated with NA/PA. The findings suggest that people who experience NA have high levels of adaptive and maladaptive perfectionism (particularly CM, DA, SPP, EC and PStr), tend to perceive high stress and to perceive themselves as having low coping while facing stress, and tend to use all maladaptive CER strategies and fewer adaptive ones (particularly high blaming others, self-blame, catastrophizing and low positive reappraisal and planning). Conversely, people who experience PA show low levels of adaptive and maladaptive perfectionism (particularly CM, EC and PStr), tend to perceive low stress and to perceive themselves as having high resources of coping while facing stress, and tend to involve themselves in adaptive CER processes, particularly positive reappraisal and planning and positive refocusing (PA was not significantly associated with maladaptive CER strategies).

Our results are in line with those of other studies, which showed an association between perfectionism

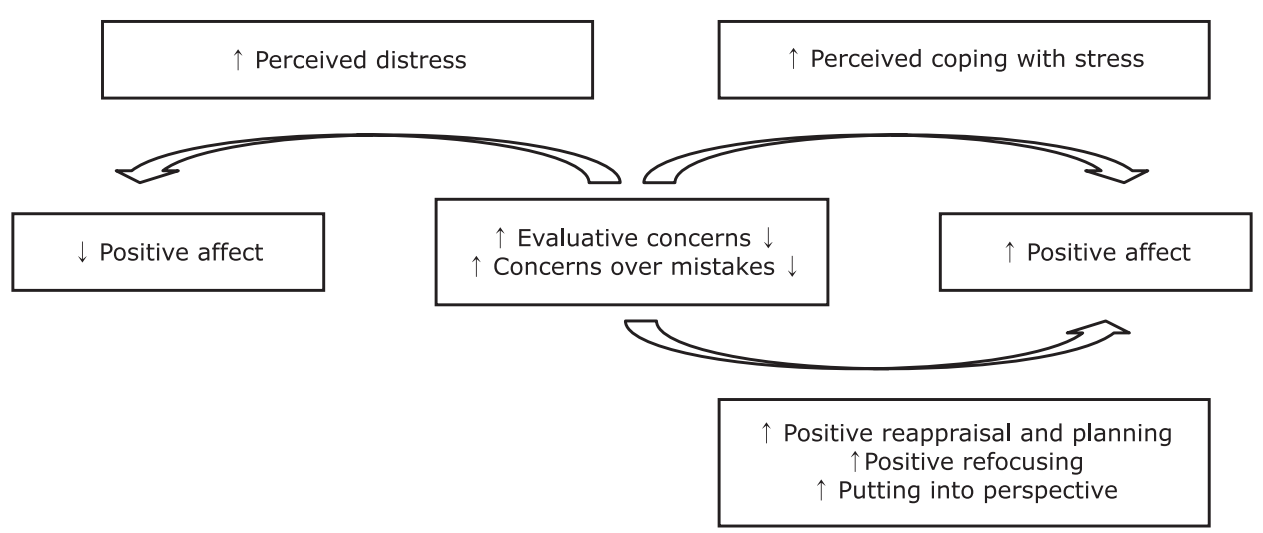

Figure 3 - Cognitive emotion regulation dimensions and perceived distress/coping mediating the association between perfectionism dimensions and positive affect. $\downarrow=$ low levels; $\uparrow=$ high levels. 
and stress and coping, and between perfectionism and NA/PA. ${ }^{26,27}$ The findings from the correlation analysis showed that maladaptive perfectionism dimensions were associated with high levels of maladaptive and low levels of adaptive CER strategies. These results were expected, since they are negative dimensions of perfectionism and have been consistently associated with negative processes and outcomes. ${ }^{6,24}$ In fact, previous literature results revealed that $\mathrm{CM}$ was associated with high levels of avoidance, negative expectation and self-blame (as coping strategies), ${ }^{19}$ that SPP was related to deficits in adaptive mechanisms, to a negative problem-solving orientation, to emotion regulation coping, to lower levels of constructive thinking ${ }^{38,39}$ and to high levels of self-blame, rumination, catastrophizing and low levels of positive reappraisal and planning and putting into perspective. ${ }^{20,22,23}$ Similarly, EC were prospectively associated with high use of avoidant coping and with low use of problem-focused and positive reinterpretation. ${ }^{27}$

In our study, maladaptive perfectionism was also related to increased perceived distress and decreased perceived coping. These results confirm the literature findings, suggesting that perfectionism is implicated in stress generation, anticipation, enhancement and maintenance. ${ }^{2,24,26,27}$

Concerning the adaptive perfectionism dimensions (PS, SOP and PStr), the significant positive correlation with perceived distress and with several maladaptive CER strategies (consistently with self-blame), as well as the absence of significant association with perceived coping and with adaptive CER, were somewhat unexpected. However, these results corroborate previous findings, showing that PS and SOP are not completely adaptive ${ }^{1,40}$ and may be involved in both positive and negative outcomes, processes and mechanisms. ${ }^{6}$ Our results also confirm the findings from other studies exploring the association between perfectionism and CER strategies, which revealed, for example, an association between SOP and self-blame, ${ }^{20,22}$ and between PS and rumination. ${ }^{19}$

Additionally, organization is a poor representation of the perfectionism construct and was not included in many studies. ${ }^{6}$ Nevertheless, it is part of several measures of perfectionism, and we decided to explore it to compare our results with those from studies which also included this dimension. Our results showed that organization was the only perfectionism dimension revealing a significant and positive relation with all adaptive CER mechanisms (excluding acceptance) and an inverse association with self-blame. It also had a protective effect against distress and was associated with lower levels of NA.
The other main goal of the present study was to consider the role of CER and perceived stress/coping in the association between perfectionism and NA/PA. A strength of this study is that the results showed how CER and perceived distress/coping mediate the associations between perfectionism and NA/PA.

Therefore, maladaptive perfectionists, who have high levels of self-critical perfectionism (EC, CM, DA and SPP), may be more vulnerable to NA, because they engage in maladaptive CER strategies (rumination, self-blame, blaming others, catastrophizing) as well as in decreased adaptive CER strategies (positive reappraisal and planning, positive refocusing and putting into perspective) and also because they experience high perceived distress, which is accompanied by low perceived resources of coping with stress. These findings were expected, since they are in line with several studies that have used different measures to assess perfectionism, perceived stress/ coping, emotion regulation and psychological distress. For instance, the results confirm the findings reported by Dunkley \& Blankstein, ${ }^{24}$ which revealed that dysfunctional coping (high emotion-oriented and distraction, low task-oriented) fully mediated the relation between maladaptive perfectionism and psychological distress. They are also in conformity with the study conducted by Dunkley et al., ${ }^{26}$ which revealed that the association between maladaptive perfectionism and NA was partially mediated by hassles and avoidant coping. Moreover, our results are in line with the prospective findings of Dunkley et al., ${ }^{27}$ which suggest that self-critical perfectionists have higher levels of event stress, avoidant coping and NA and lower levels of perceived control over stress. Finally, the finding that maladaptive perfectionists use low adaptive CER strategies that lead to NA increase complements the results of Dunkley et al., ${ }^{26,27}$ showing that low task-oriented coping mediated the association between maladaptive perfectionism and psychological distress. Then, when maladaptive perfectionists engage in problem-focused and positive reinterpretation, they may experience greater decreases in negative emotions, such as in sadness. ${ }^{27}$ Therefore, the use of adaptive coping/CER may be particularly effective in well-being promotion in self-critical perfectionists.

Our results also indicate that subjects with high EC and excessive CM are also more vulnerable to experiencing low PA because they generate high levels of perceived distress. High self-critical perfectionists may be more reactive to stressors and feel lower perceived control ${ }^{26}$ and may be more vulnerable to experiencing less PA in the future when daily problems are more stressful than usual and when they perceive low control over stress. ${ }^{27}$ 
There is an increasing recognition that PStr is more associated with positive characteristics.5,6 Our findings support the assumption that PStr may sometimes be associated with $\mathrm{NA}^{41}$ and that this association is mediated by perceived distress and maladaptive CER strategies (PStr and adaptive CER were not significantly associated). Adaptive perfectionists (high in PStr) are prone to NA because they experience rumination, blaming others, catastrophizing, and particularly self-blame, and because they generate high levels of perceived distress. These results are in line with the findings of Blankstein \& Dunkley, ${ }^{25}$ which suggested that adaptive perfectionism interacts with hassles, and that perceived stress may lead to distress in adaptive perfectionists. They are also in agreement with the prospective findings of Dunkley et al., ${ }^{27}$ which showed that adaptive perfectionism interacts with both future event stress and avoidant coping to predict NA and sadness.

Adaptive perfectionism, which implicates the setting of high standards and the motivation to attain perfection, may be accompanied by increased selffocus, involving self-critical tendencies when goals are not attained or when failures are faced. Therefore, due to self-discrepancies in face of an inability to comply with one's own standards, which is perceived as a failure, adaptive perfectionists may engage in maladaptive coping strategies. They may ruminate on negative life experiences and failures, catastrophize, blame others, and in particular blame themselves for negative outcomes, ${ }^{27,38}$ which in turn may determine maladjustment, including increased perceived distress and NA. Maladaptive CER strategies (e.g., rumination), which are predicted by both maladaptive and adaptive perfectionism, may also maintain perceived distress and NA, because they are ineffective in dealing with $N A$, intensify negative thinking and contribute to impairments in problem solving. ${ }^{15}$

Concerning perfectionism and PA association, our results revealed that lower levels of $\mathrm{CM}$ and $\mathrm{EC}$ were associated with higher levels of adaptive CER dimensions (particularly positive reappraisal and planning, positive refocusing and putting into perspective), and with higher perceived coping, which in turn promoted PA. These results are in agreement with those of Dunkley et al., ${ }^{27}$ which indicated that individuals with higher selfcritical perfectionism, comparing to those with lower levels, prospectively showed greater decreases in PA when experiencing more stressful events, and perceived less control over stress than usual. However, they may also experience greater increases in PA when they use more problem-focused-coping than usual.

Overall, the results from the mediation analyses support the diathesis-stress and coping model ${ }^{42}$ of the relationship between perfectionism and NA. Thus, high perfectionists (diathesis) exposed to life stress are more vulnerable to psychological distress, because they use ineffective coping strategies and perceive high stress levels and low coping resources.

Both our results and those reported by Dunkley et al. ${ }^{27}$ suggest that the variability in levels of maladaptive perfectionism leads to variability in PA, and that the effect of perfectionism on perceived distress/coping and adaptive coping/CER may contribute to it. These findings support the risk-resilience continuum model of the relationship between maladaptive perfectionism and PA. Therefore, at the extreme of the high vulnerability end of the spectrum, high maladaptive perfectionism is associated with high levels of perceived distress and, as a consequence, with Iow PA. At the other end of the spectrum, low maladaptive perfectionism seems to be a resilience factor, because it is associated with no significant levels of distress and with significantly high perceived coping with stress and adaptive CER, and may promote PA.

The results of the present study may have applications in the prevention of and intervention for NA. Perfectionists could benefit from specific psychological interventions targeting the modification of cognitive $\mathrm{CM}$, doubts about performance quality, cognitions related to the importance of being perfect, nonacceptance of imperfection and conditional acceptance, appraisals of stress/coping with stress and negative CER mechanisms. These interventions could also promote positive CER, particularly positive reappraisal and planning and positive refocusing, which promote PA and include support or direct education focusing on orderliness/organization skills.

The participants of the present study were medical students, which limits the generalization of results. Future studies should be conducted with other populations, including clinical samples. The cross-sectional nature of this study is another limitation, as prospective studies are the most adequate ones to study causality between variables. Furthermore, considering the evidence that there are gender differences in CER and affectivity, ${ }^{43}$ future studies exploring gender specificities may contribute to a better understanding of this issue.

Adaptive perfectionism predicted NA, and maladaptive perfectionism predicted NA and low PA. Low maladaptive perfectionism predicted high PA, and CER strategies and perceived distress/coping with stress had an important mediation role in these associations.

The results of this study may have clinical implications. NA prevention and treatment models for use with university students may focus on maladaptive and adaptive components of perfectionism and their impact on CER strategies, stress and coping resource appraisal. 


\section{Disclosure}

No conflicts of interest declared concerning the publication of this article.

\section{References}

1. Frost $R$, Marten $P$, Lahart $C$, Rosenblate $R$. The dimensions of perfectionism. Cognit Ther Res. 1990;14:449-68.

2. Hewitt PL, Flett G. Perfectionism and stress in psychopathology. In: Flett G, Hewitt PL, editors. Perfectionism: theory, research and treatment. Washington DC: American Psychological Association Press; 2002. p. 255-84.

3. Egan SJ, Wade TD, Shafran R. Perfectionism as a transdiagnostic process: a clinical review. Clin Psychol Rev. 2011;31:203-12.

4. Hewitt PL, Flett G. Perfectionism in the self and social contexts: conceptualization, assessment, and association with psychopathology. J Pers Soc Psychol. 1991;60:456-70.

5. Stoeber J, Stoeber F. Domains of perfectionism: prevalence and relationships with perfectionism, gender, age and satisfaction with life. Pers Individ Dif. 2009;46:530-5.

6. Stoeber J, Otto K. Positive conceptions of perfectionism: approaches, evidence, challenges. Pers Soc Psychol Rev. 2006; 10:295-319.

7. Bieling P, Israeli A, Antony M. Is perfectionism good, bad, or both? Examining models of the perfectionism construct. Pers Individ Dif. 2004;36:1373-85

8. Keogh E, Reidy J. Exploring the factor structure of the Mood and Anxiety Symptom Questionnaire (MASQ). J Pers Assess. 2000;74:106-25.

9. Böhnke JR, Lutz W, Delgadillo J. Negative affectivity as a transdiagnostic factor in patients with common mental disorders. J Affect Disord. 2014;166:270-8.

10. Watson D, Clark LA. Negative affectivity: the disposition to experience aversive emotional states. Psychol Bull. 1984; $96: 465-90$.

11. Hankin BL, Abela JRZ. Development of psychopathology: a vulnerability-stress perspective. California: Sage Publications; 2005.

12. Weisman AN, Beck AT. Development and validation of the dysfunctional attitudes scale: a preliminary investigation. Paper presented at Annual Meeting of The American Educational Resdarch Association; Toronto, Canada, 1978.

13. Stoeber J, Kobori O, Tanno Y. The Multidimensional Perfectionism Cognitions Inventory-English (MPCI-E): reliability, validity, and relationships with positive and negative affect. ] Pers Assess. 2010;92:16-25.

14. Burns LR, Fedewa BA. Cognitive styles: links with perfectionistic thinking. Pers Individ Dif. 2005;38:103-13.

15. Nolen-Hoeksema S,Wisco BE, Lyubomirsky S. Rethinking rumination. Perspect Psychol Sci. 2008;3:400-24.

16. Gross J, Muñoz R. Emotion regulation and mental health. Clin Psychol Sci Prac. 1995;2:151-64.

17. Garnefski N, Kraaij V Spinjoven P. Negative life events, cognitive emotion regulation, and emotional problems. Pers Individ Dif. 2001;30:1311-27.

18. Garnefski N, Kraaij V. The Cognitive Emotion Regulation Questionnaire. Psychometric features and prospective relationships with depression and anxiety in adults. Eur J Psychol Assess. 2007;23:141-9.

19. Ogai Y. Relationship between two aspects of self-oriented perfectionism and self-evaluative depression: using coping styles of uncontrollable events as mediators. Shinrigaku Kenkyu. 2004; 75:199-206

20. Rudolph SG, Flett G, Hewitt PL. Perfectionism and deficits in cognitive emotion regulation. J Ration Emot Cogn Behav Ther. 2007;25:343-57.

21. Fredrickson $\mathrm{BL}$. The role of positive emotions in positive psychology: the broaden-and-build theory of positive emotions. Am Psychol. 2001;56:218-26.

22. Hewitt $\mathrm{PL}$, Flett G. Dimensions of perfectionism in unipolar depression. J Abnorm Psychol. 1991;100:98-101.
23. Flett G, Madorsky D, Hewitt P, Heisel M. Perfectionism cognitions, rumination, and psychological distress. J Ration Emot Cogn Behav Ther. 2002;20:33-47.

24. Dunkley DM, Blankstein KR. Self-Critical perfectionism, coping, hassles, and current distress: a structural equation modeling approach. Cognit Ther Res. 2000;24:713-30.

25. Blankstein K, Dunkley D. Evaluative concerns, self-critical, and personal standards perfectionism: a structural equation modeling strategy. In: Flett $\mathrm{G}$, Hewitt $\mathrm{PL}$, editors. Perfectionism: theory, research and treatment. Washington DC: American Psychological Association Press; 2002, p. 285-315.

26. Dunkley DM, Zuroff DC, Blankstein KR. Self-citical perfectionism and daily affect: dispositional and situational influences on stress and coping. J Pers Soc Psychol. 2003;84:234-52.

27. Dunkley DM, Mandel T, Ma D. Perfectionism, neuroticism, and daily stress reactivity and coping effectiveness 6 months and 3 years later. J Couns Psychol. 2014;61:616-33.

28. Soares MJ, Gomes A, Macedo A, Santos V, Azevedo M. Escala Miltidimensional de Perfeccionismo: adaptação à população portuguesa. Rev Port Psicossom. 2003; 5:47-55.

29. Amaral AP, Soares MJ, Pereira AT, Bos SC, Marques M, Valente J, et al. Frost Multidimensional Perfectionism Scale: the portuguese version. Rev Psiquiatr Clin. 2013;40:144-9.

30. Soares MJ, Azevedo J, Pereira AT, Araújo A, Castro J, Chaves B, Roque C, Bajouco M, Macedo A. Confirmatory factor analysis of the Frost et al Multidimensional Perfectionism Scale-24 (F-MPS 24). Paper presented at 25th European Congress of Psychiatry, Italy, 2017.

31. Soares MJ, Amaral AP, Pereira AT, Bos SC, Marques M, Valente J, et al. Multidimensional perfectionism scales underlying higher order factors. In: Kaniaty K, Moore KA, Howard S, Buchwald $P$, editors. Stress and anxiety applications to social and environmental threats. Psychological well-being, occupational challenges, and developmental psychology. Berlin: Logos Verlag Berlin GmdH; 2014. p.115-25.

32. AzevedoM,SilvaC,DiasM. Operfildeestadosdehumor: adaptação à população portuguesa. Psiquiatr Clin. 1991:12:187-93.

33. Cohen S, Kamarck T, Mermelstein R. A global measure of perceived stress. J Health Soc Behav. 1983;24:385-96.

34. Castro J, Soares MJ, Pereira AT, Chaves B, Macedo A. Questionário da Regulação Emocional Cognitiva: validação para a população portuguesa. Psiquiatr Clin. 2013;34,101-9.

35. Cohen J. A power primer. Psychol Bull. 1992;112:155-9.

36. Preacher KJ, Hayes AF. SPSS and SAS procedures for estimating indirect effects in simple mediation models. Behav Res Methods Instrum Comput. 2004;36:717-31.

37. Preacher $\mathrm{KJ}$, Hayes AF. Asymptotic and resampling strategies for assessing and comparing indirect effects in multiple mediator models. Behav Res Methods Instrum Comput. 2008; 40:879-91.

38. Hewitt PL, Flett G, Endler N. Perfectionism, coping and depression symptomatology in a clinical sample. Clin Psychol Psychother. 1995;2:47-58.

39. Flett G, Hewitt PL, Endler NS, Tassone C. Perfectionism and components of state and trait anxiety. Curr Psychol. 1994; 13:326-50.

40. DiBartolo PM, Li CY, Frost RO. How do the dimensions of perfectionism relate to mental health? Cognit Ther Res. 2008;32:401-17.

41. Soares MJ, Amaral AP, Pereira AT, Bos S, Madeira N, Nogueira V, et al. In the search of pure negative vs. positive multidimensional perfectionism. Using previous literature findings as a guide. Abstract Book - WPA. 2014;4.

42. Lazarus RS, Folkman S. Stress, appraisal, and coping. New York: Springer; 1984.

43. Lipovcan LK, Prizmic Z, Franc R. Age and gender differences in affect regulation strategies. Zagreb: DrustvenaIstrazivanja; 2009.

\section{Correspondence:}

Juliana Castro

Departamento de Psicologia Médica, Faculdade de Medicina, Universidade de Coimbra

Rua Larga, 3004-504

Coimbra, Portugal

E-mail: jsc.fmuc@gmail.com 